three-fourths of its terrors; and all this has been accomplished by prolonged research (extending over ten years) on physiological lines without the aid of any specific bacterial or medicinal agent.

Bibliography.-1. Indian Medical Gazette, March, 1908, p. 90 ; Transactions of the Bombay Meclical Congress, 1909; Proceedings of the Royal Society, B, vol. lxxi.. p. 291, 1909 ; Ther. Gazette, Nov. 15th, 1910; Indian Merical Gazette, p. 401, 1909; Brit. Med. Jour., vol. ii., p. 835, 1910. 2. Brit. Med. Jour., Nov. 18th 1911. 3. Indian Medical Gazette, p. 497, 1910. 4. China Medical Journal, March, 1912. 5. TeE LANCET, vol. Hi., p. 1424, 1912. 6. Indian Medical Gazette, p. 401, 1914. 7. Ibid., p. 9, 1913. 8. Ibid p. 401, 1909. 9. Philippine Journal of Science, B, vol. $\nabla$, p. 363, 1910. 10 Indian Journal of Medical Research, vol. ii . p. 867, 1915. 11 American Journal of Tropical Diseases, vol. i1., p. 104, 1914. 12. Transactions of the Royal Medical and Chirurgical Society, vol. Ixxvi., 1894.

Calcutta.

\section{REMOVAL OF A SHRAPNEL TIME-FUSE FROM THE LEFT SHOULDER :} DESCRIPTION OF A SPLINT.

By A. E. MORTIMER WOOLF, M.B., B.C. CAMB., F.R.C.S. ENG., TEMPORARY LIEUTENANT, R.A.M.C.

Is removing foreign bodies from various parts of the body I have often noticed the rarity of finding a piece of shell of any considerable size. Quite large wounds may be caused by a projectile of astonishingly small dimensions. Before this case the largest piece of shell I have removed had penetrated the knee-joint, completely severing the internal condyle of the femur from the rest of the bone. In this case the portion of shell did not measure one cubic inch. The lodgment of a complete shrapnel time-fuse in almost perfect condition is an event of such rare occurrence that it seems to be worth while placing it on record.

Fig. 1.

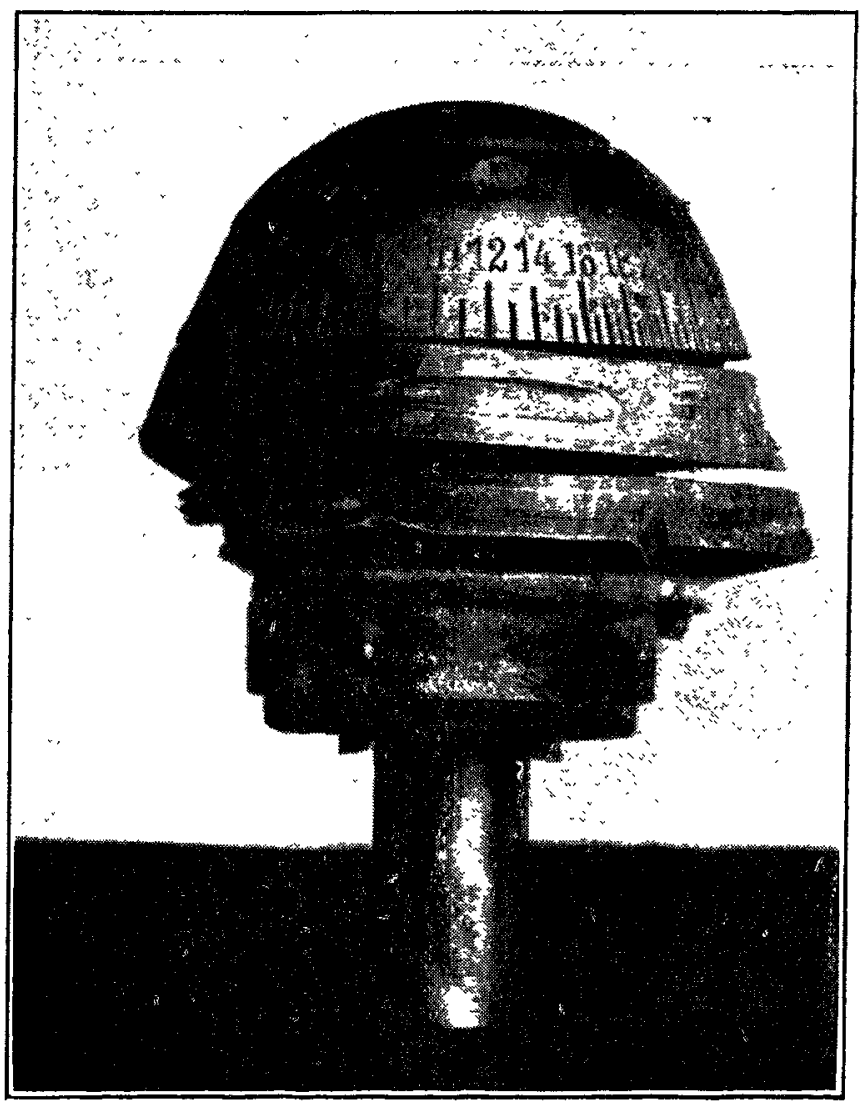

Time-fuse removed from wound of shoulder (actual size).

The patient was wounded on May 25th at about 2.30 P.M. He is a stretcher bearer, and was going up to the trenches to collect wounded. He advanced to within about four yards of his destination when he heard the shriek of a shell approaching.
He turned his back on the trenches and almost immediately felt a severe blow on the back of the left shoulder. The blow did not knock him down, but caused him to stagger. He reached a ditch about 100 yards away, where he fell down, and in about 20 minutes was removed to the dressing station, where his wound was dressed and painted with iodine. That night he was taken to the clearing station, where under an anæsthetic a tube was inserted. On the following day he was sent to another clearing station and then despatched on the train, arriving at a general hospital at the base three days after the reception of the original injury.

On admission the patient was in considerable pain, much more so than is usually the case. There was a wound over the posterior border of the deltoid about $1 \frac{1}{2}$ inches long, through which a tube had becn inserted. The other end of the tube appeared through a much smaller wound situated over the pectoro-deltoid interval. This wound looked like an operation incision, and, the patient thinks, was not caused by the original injury.

Owing to the severity of the pain he was taken to the theatre almost immediately. On inserting my finger into the posterior wound I encountered a round smooth object which for the moment I thought was the head of the humerus, dislocated and externally rotated. On retracting the edges of the wound I saw the piece of hrass at the tnp of the round part of the time-fuse, and immediately recognised the cause of the trouble. The fuse was tightly impacted and the greatest convexity was situated about inch from the surface. The wound had to be enlarged considerably to allow of removal, which was accomplished without difficulty. There was a comminuted fracture of the humerus below the surgical neck; some loose fragments of bone were removed, and the sharp-pointed ends of the upper and lower fragments were excised with bone-cutting forceps; drainage was provided for

The fuse was lying with the stem against the bone. The fracture, though a severe one, was not nearly so comminuted as that caused by many a smaller piece of shell. On removal there were septic pieces of muscle attached in the cracks of the split metal and the odour was most revolting.

FIG. 2,

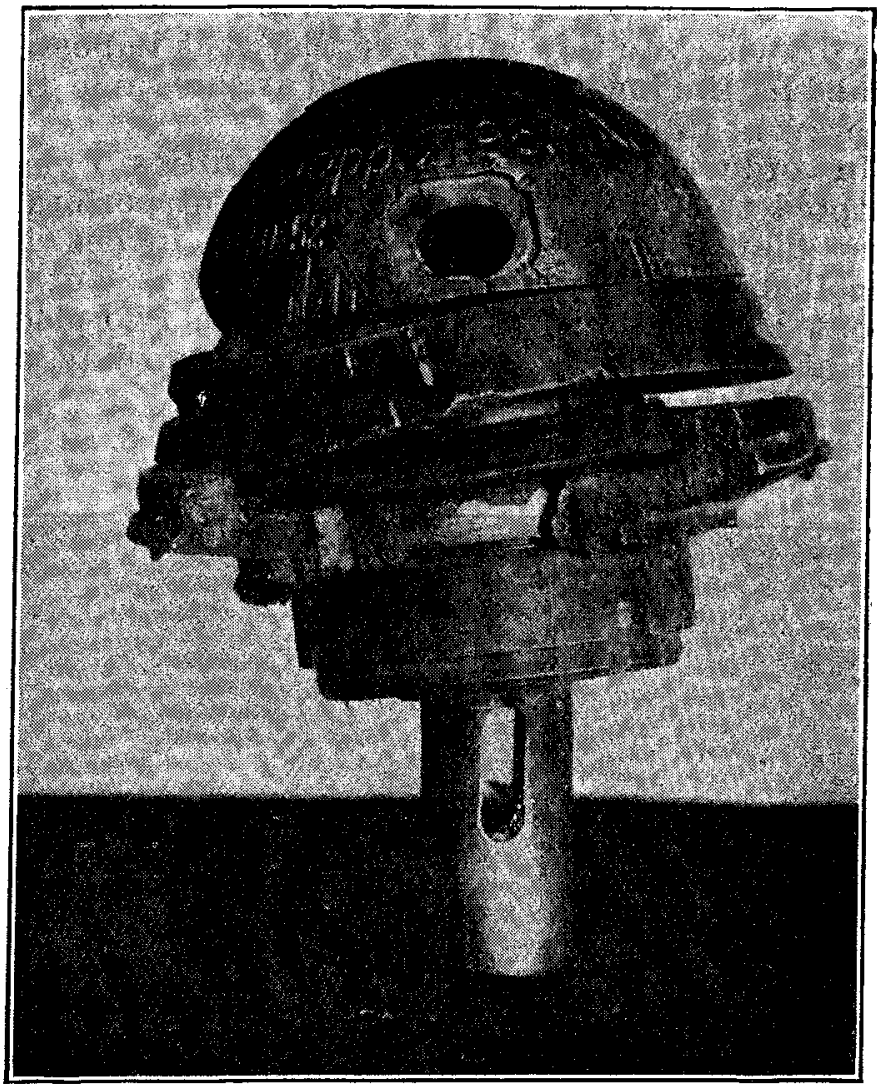

Another view of same.

Figs. 1 and 2 show two views of the specimen in nearly perfect condition. The stem of the fuse was lying nearly horizontal, with a slight inclination downwards. I suspected that the injury was due to 
FIG. 3.

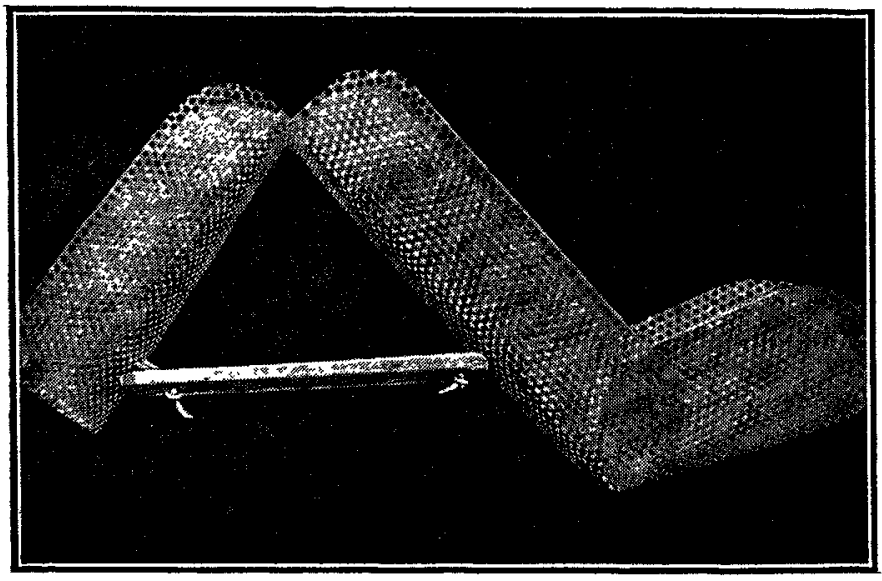

Showing the thoracic, arm, and forearm pieces of the splint, with the piece of wood securing rigidity.

a ricochet, but on questioning the patient afterwards he was unable to throw any light on this question. The weight of the fuse is 10 ounces.

In the treatment of compound fractures of the upper end of the humerus due to projectiles two difficulties are encountered: (1) the application of a retentive apparatus; and (2) the dressing of a wound without it being necessary to remove the splint. For fractures below the shoulder the modified Thomas's splint is excellent and fulfils both these requirements, at the same time allowing the lower fragment to be placed in any degree of abduction necessary. It is, unfortunately, not applicable to wounds high up, as the circular band interferes with the dressing. In order to obviate this a splint of the Thomas's variety, but modified I lbelieve by Mr. Robert Jones, has been supplied, with the upper collar so made that it fits closely to the neck and so gives access to the wound. The one drawback to this splint is that it is impossible tolabduct the lower fragment and at the same time to prevent internal rotation.

In order to obviate these difficulties I have adopted the following plan. A piece of perforated zinc plating, measuring 23 by $8 \frac{1}{2}$ inches and supplied in the army fracture boxes, is cut for about $1 \frac{1}{2}$ inches, on both sides and in two places, one about $7 \frac{1}{2}$ inches from the end of the plate, and

FIG. 5.

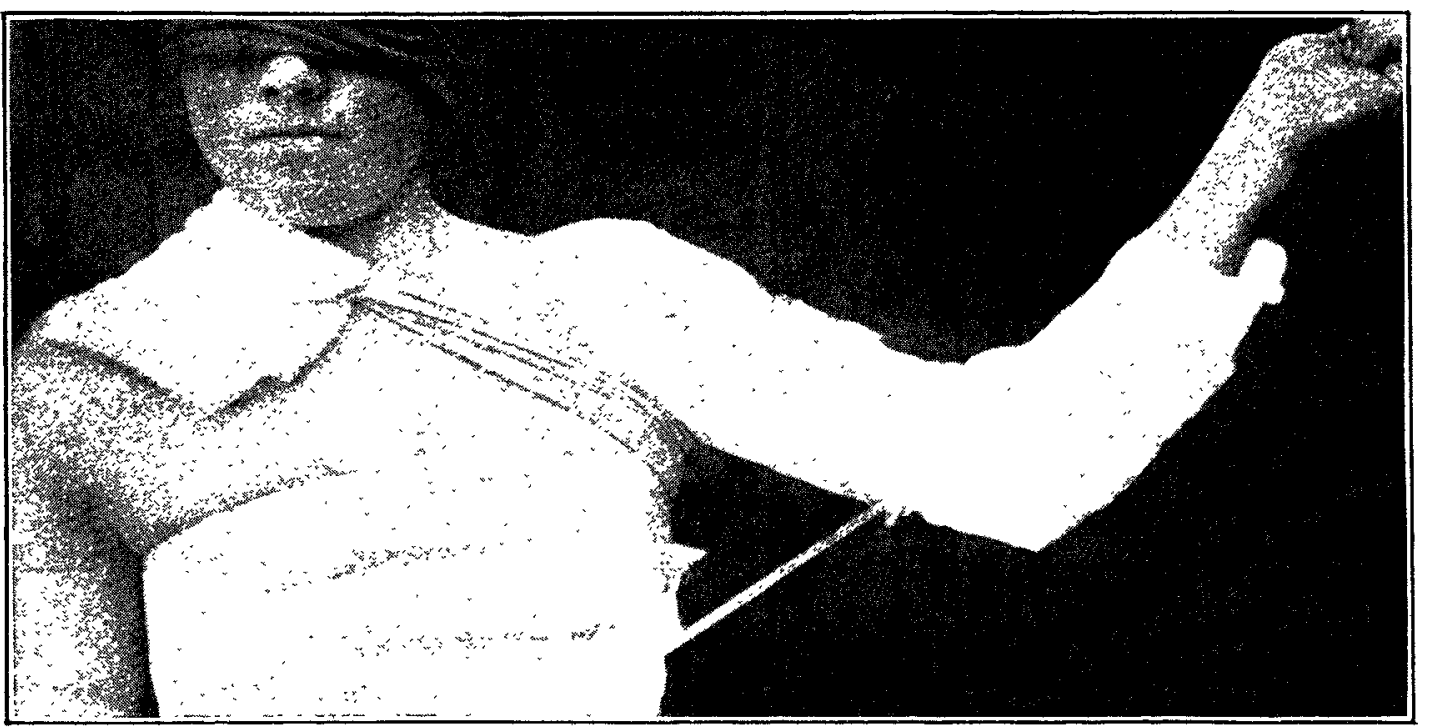

A patient with the splint applied. the second about 6 inches from the other end. The plate so cut is bent as shown in Fig. 3, so that a thoracic piece, arm piece, and forearm piece are formed. The position of the actual cuts should be determined roughly by the dimensions of the patient. The cuts are easily made by any strong pair of shears, such as plaster-of-Paris shears or even a strong pair of scissors. The very flexible plating is now moulded to the shape of the parts to which it is to be applied, and is cut away where it interferes with the subsequent dressing. The sharp corners are rounded off, and rigidity is obtained by the following methods.

Two holes are bored at each end of a piece of wood about $7 \frac{1}{2}$ by $2 \frac{1}{2}$ inches. A piece of string is threaded through the two holes, threaded through two opposite holes in the zinc plating, the ends crossed over and threaded back again through the zinc plating into the holes in the wood By this means the string end which was originally

FIG. 4.

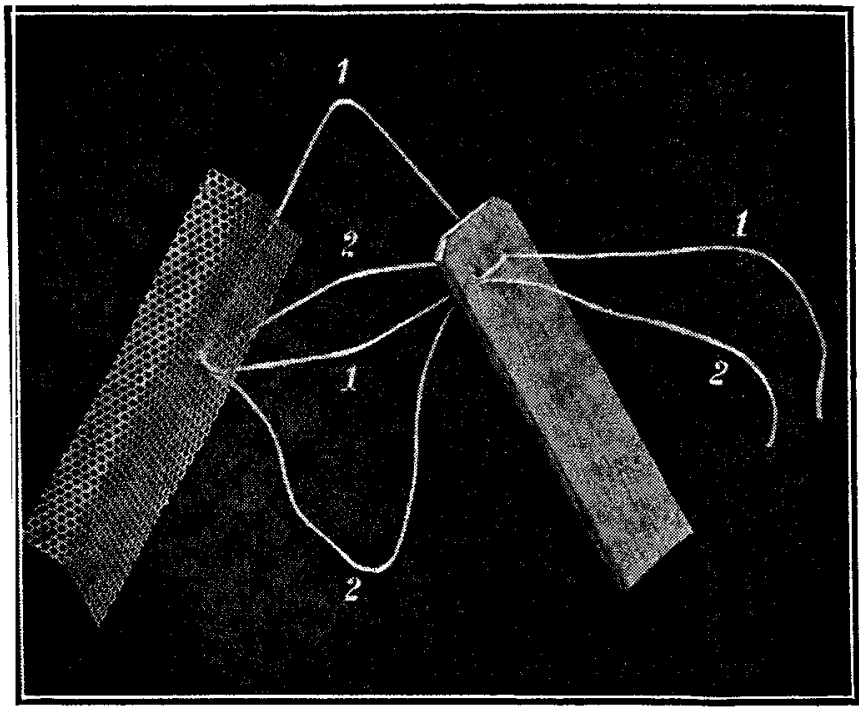

Threading the plate and piece of wood.

threaded through the right-hand hole in the wood, finally emerges through the left-hand hole. The wood is then firmly fixed by tying at both ends. (Fig. 4.) The distance between the middle of the wood and the apex of the axillary piece should be about 4 inches, so as to allow a bandage to be passed easily through this space. The forearm piece which is bent up will allow holes in the plating of this portion to come into opposition with holes in the arm piece, and string is threaded through in precisely the same way as described above, on each side, in order to secure rigidity between the two pieces.

The thoracic piece should be bandaged to the chest separately, and before starting to bandage the arm. The 
arm is bandaged over the highest point of the shoulder and under the axillary piece, and then down the arm and forearm. In dressing the case it is only the latter bandage that is removed; the bandage fixing the thoracic piece to the chest keeps the splint in position while the dressing is carried out. Extra security can be obtained by passing a triangular bandage under the axillary piece and tying over the shoulder of the opposite side, as shown in Fig. 5.

I have now used this splint on 12 cases and have found it very satisfactory. It is easily applied while the patient is under the anæsthetic, and takes about 15 to 20 minutes to complete. By making each splint at the time of operation the individual requirements of a particular case are catered for. After the operation the patient is quite comfortable, rigidity is adequate, and subsequent dressings are much facilitated.

\section{PERSISTENCE OF ANTIBODIES IN THE BLOOD OF INOCULATED PERSONS AS ESTIMATED BY AGGLUI'INA- TION TESTS. ${ }^{1}$}

\section{By GEORGES DREYER, M.A. OXON.,} M.D. COPENHAGEN,

FELLOW OF IINCOLN COLIEGE, PROFESSOR OF PATHOLOGY IN THE UNIFEESITY OF OXFORD;

$$
\text { AND }
$$

A. C. INMAN, M.A., B.M. OXON.,

DIRECTOR OF THE CLINICAL LABORATORY, BROMPTON HOSPITAL, LONDON.

(From the Laboratory of the British Red Cross Hospital No. 4: Sir HENRY NoRMaN's.)

In the course of work carried out recently in the British Red Cross Hospital No. 4 by the kind invitation of Sir Henry Norman, Bart., M.P., to whose hospitality we were entirely indebted, and who fitted up a laboratory expressly for the purpose, we investigated the agglutinin content of the blood in a number of normal inoculated persons. Our work was facilitated, and in fact only made possible, by the kindness of Colonel Sir William Leishman, F.R.S., and Lieutenant-Colonel Evans, C.O., 14th Stationary Hospital, who with his staff generously placed at our disposal the extensive material at their command.

All the normal individuals examined (officers and privates, nurses, and Red Cross orderlies) had received one or two doses of army typhoid vaccine within the period from August, 1914, to the end of March, 1915. The agglutination tests were carried out in the course of the last ten days of April. The method employed was that already fully described elsewhere by one of us (G.D. ${ }^{2}$ ), and the use of standardised agglutinable cultures rendered the results obtained entirely comparable.

To facilitate the survey of these results they are arranged in the accompanying table in four groups:-

Group I. contains persons not previously inoculated, who received two doses of vaccine with an interval of about ten days between the doses.

1 The expenses of this work have been defrayed out of a grant received from the National Medical Research Committee.

2 Dreyer, Georges : Widal's Reaction with Sterilised Cultures, Hospitalstidende, No. 19, 1906, and Journal of Pathology and Bacteriology, vol. xiii., 1909.

3 Dreyer, Georges; Walker, E. W. Ainley; and Gibson, A. G. Typhoid and Paratyphoid Infection in Relation to Antityphoid Inoculation, The LaNCHT, Feb. 13th, 1915.
Group II. contains the persons who had previously been inoculated (within the preceding six years), and who on this occasion received two doses of vaccine with an interval of about ten days between the doses.

Group III. comprises persons not previously inoculated who received only a single dose of vaccine.

Group IV. consists of persons previously inoculated (within the last six years) who received on this occasion only a single dose of vaccine.

The table gives all essential details. Two different standard agglutinable cultures were used in the course of the work, and the final results are stated in terms of the standard agglutinin unit.

Results of Agglutination Tests.

\begin{tabular}{|c|c|c|c|c|c|c|c|c|c|}
\hline 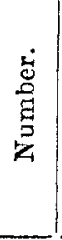 & 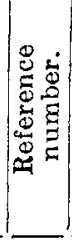 & $\begin{array}{c}\text { Date of } \\
\text { inoculation. }\end{array}$ & 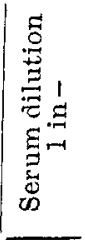 & 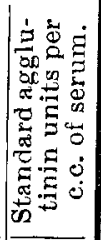 & 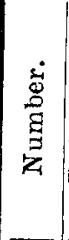 & 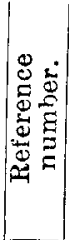 & $\begin{array}{c}\text { Date of } \\
\text { inoculation. }\end{array}$ & 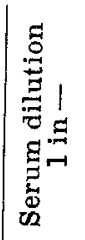 & 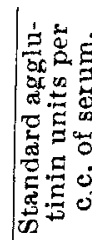 \\
\hline & & Group $I$. & & & 39 & 30 & Dec., 1914. & 750 & \\
\hline 1 & 1 & Sept., 1 & 375 & 150 & 40 & $44 a$ & 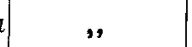 & 190 & \\
\hline 2 & 2 & ", & 375 & 70 & 41 & 37 & $"$ & 375 & \\
\hline 3 & 3 & Oct., 1914. & 7500 & 1390 & 42 & 31 & , & 360 & \\
\hline 4 & 7 & ", & 1875 & 750 & 43 & 32 & , & 360 & \\
\hline 5 & 8 & , & 875 & 350 & 44 & 27 & , & 150 & \\
\hline 6 & 6 & , & 1875 & 348 & 45 & 28 & , & 90 & \\
\hline 7 & 5 & , & 700 & 130 & 46 & 48 & Jan., I9 & 875 & 162 \\
\hline 8 & 4 & ", & 375 & 70 & 47 & 49 & , & 190 & \\
\hline 9 & 20 & Nov., 1914. & 3125 & 580 & 48 & 47 & , & 330 & \\
\hline 10 & 21 & ," & 3125 & 580 & 49 & 46 & , & 320 & \\
\hline 11 & 12 & , & 750 & 300 & 50 & 50 & & 90 & \\
\hline 12 & 26 & ", & 750 & 300 & 51 & 45 & 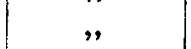 & 190 & 35 \\
\hline 13 & 25 & ", & 1500 & 278 & 52 & 51 & Feb., 1915. & 750 & 300 \\
\hline 14 & 22 & $"$ & 875 & 162 & 53 & 52 & ", & 190 & 76 \\
\hline 15 & 9 & $"$ & 375 & 150 & 54 & 53 & , & 150 & 60 \\
\hline 16 & 15 & , & 750 & 139 & 55 & 55 & March, 1915. & 3750 & 1500 \\
\hline 17 & 17 & , & 750 & 139 & 56 & 54 &, & 1500 & 278 \\
\hline 18 & 24 & , & 730 & 135 & \multicolumn{5}{|c|}{ Group $I I}$. \\
\hline 19 & 14 & , & 330 & 61 & 57 & 56 & Nov., 1914. & 1875 & 348 \\
\hline 20 & 16 & " & 330 & 61 & 58 & 57 & $"$ & 750 & 139 \\
\hline 21 & 23 & , & 330 & 61 & 59 & 59 & $"$ & 750 & 139 \\
\hline 22 & 13 & ," & 320 & 59 & 60 & 60 & , & 700 & 130 \\
\hline 23 & 11 & , & 90 & 36 & 61 & 58 & & 330 & 61 \\
\hline 24 & 18 & ", & 90 & 35 & 62 & 61 & Jan., 1915. & 330 & 132 \\
\hline 25 & 19 & ", & 190 & 35 & \multicolumn{5}{|c|}{ Group III. } \\
\hline 26 & 10 & & 75 & 30 & 63 & 65 & Sept., 1914. & 140 & 56 \\
\hline 27 & 43 & Dec., 1914. & 7500 & 1390 & 64 & 62 & ," & 90 & 36 \\
\hline 28 & 42 & ", & 3125 & 580 & 65 & 63 & , & 90 & 36 \\
\hline 29 & 4 & , & 1500 & 278 & 66 & 64 & ", & 90 & 36 \\
\hline 30 & 41 & $"$ & 1500 & 278 & 6 & 66 & Oct., 1914. & 190 & 76 \\
\hline 31 & 36 & ," & 1500 & 278 & 68 & 68 & Feb., 1915. & 375 & 150 \\
\hline 32 & 34 & , & 1500 & 278 & 69 & 67 & & 150 & 60 \\
\hline 33 & 38 & , & 875 & 162 & 70 & 70 & March, 1915 & 3125 & 1250 \\
\hline 34 & 39 & , & 750 & 139 & 71 & 69 & & 1500 & 600 \\
\hline 35 & 40 & ", & 750 & 139 & \multicolumn{5}{|c|}{ Group IV. } \\
\hline 36 & 35 & " & 750 & 139 & 72 & 71 & Aug., 1914. & 1600 & 600 \\
\hline 37 & 33 & " & 750 & 139 & 73 & 72 & - & 750 & 300 \\
\hline 38 & 29 & ", & 750 & 139 & 74 & 73 & $"$ & 75 & 30 \\
\hline
\end{tabular}

The importance of the latter method of expressing results is well brought out in the present series of observations, since with different standard agglutinable cultures agglutination in the same serum dilution does not necessarily imply the presence of the same number of standard agglutinin units in the serum. For owing to the different agglutinability of different cultures each standard agglutinable culture has its own particular reduction factor for calculating the number of standard agglutinin units in any given serum tested. This unit was E 2 